\title{
A Revista Careta e a instituição de saberes religiosos nos discursos para a educação feminina (1914-1918)
}

\author{
The Careta Magazine and the institution of religious \\ knowledge in the speeches for female education (1914- \\ 1918)
}

Fernanda Conceição Costa Frazão

Doutoranda em Educação na Universidade Federal do Paraná, Curitiba, Brasil, nandac75@gmail.com

\section{Resumo}

Este trabalho trata da educação feminina nos enunciados da revista Careta, com recorte para o saber religioso percebido nos conteúdos em circulação no periódico. A leitura da fonte histórica foi problematizada a partir da análise do discurso proposta por Michel Foucault (2010), motivada pela percepção de um arranjo discursivo constituído por saberes elaborados por diferentes instituições, mas que orquestravam-se no propósito de orientar 0 comportamento feminino em determinados padrões sociais. Papéis sociais femininos foram colocados em circulação e aqui estão analisados sob a perspectiva de elaborar sobre como os saberes religiosos contribuíram para o regime de verdade de um discurso que se propõe um alcance nas práticas.

Palavras-chave: Educação Feminina. Revista Careta. Análise do discurso. Saberes religiosos.

\section{Abstract}

This work deals with the female education in the statements of the magazine Careta, with a cut to the religious knowledge perceived in the contents in circulation in the periodical. The reading of the historical source was problematized from the analysis of the discourse proposed by Michel Foucault (2010), motivated by the perception of a discursive arrangement constituted by knowledge elaborated by different institutions, but which were orchestrated in the purpose of orienting the female behavior in certain social patterns. Feminine social roles were put into circulation and are analyzed here from the perspective of elaborating on how religious knowledge contributed to the truth regime of a discourse that proposes a reach in practices

Keywords: Female Education. Magazine Careta. Speech analysis. Religious knowledge. 


\section{Os discursos da revista Careta: fonte histórica e objeto de análise}

Este trabalho analisa os discursos para a educação feminina na revista Careta, colocando luz sobre os saberes religiosos na composição dos enunciados do periódico. Em pesquisa mais ampla foram investigados indícios sobre práticas educativas para mulheres na revista, utilizada como fonte histórica. De circulação nacional, a Careta foi editada no Rio de Janeiro entre os anos de 1908 e 1960, com publicações semanais; desse universo total de publicações, foi realizado um recorte temporal de 1914 a 1918.

O critério que gerou esse primeiro marco temporal foi a disponibilidade de números de revistas entre 1912 e 1918, localizados no arquivo do Instituto do Patrimônio Histórico e Artístico Nacional (IPHAN), na cidade de São João delRei-MG. Para o recorte dos anos 1914 a 1918, eventos como o governo presidencial de Wencesláo Braz e da I Guerra Mundial foram observados pela alusão ao silenciamento institucional às mulheres na interdição delas para produção de discursos políticos, o que é atravessado por outros silenciamentos, como é o caso da religião cristã, predominantemente praticada no Brasil no contexto histórico em debate, que não dispõe de acesso de mulheres ao clero, que contém as posições hierárquicas mais relevantes da sua organização ${ }^{2}$.

Os conteúdos da Careta se apresentaram como possibilidade para análise de conteúdo educacional que fosse além das práticas escolares: textos, fotografias, charges, propagandas em certa medida instrutivos, no cumprimento de um papel educativo da imprensa de informar, fazer circular opiniões e saberes, estabelecer padrões de conduta, de comportamento e de civilidade.

É possível encontrar diversas esferas sociais e instituições que se preocupavam com os papéis femininos. Dentre elas, que deliberavam sobre os modos de ser e de viver das mulheres estavam a "medicina e a imprensa", que se dedicavam "na formulação de uma série de propostas que visavam educar a mulher para o seu papel de guardiã do lar e da família” (D'Incao, 1997, p. 230).

$\mathrm{Na}$ leitura do semanário destacaram-se imagens de mulheres, produtos diversos para elas, a beleza, a conduta feminina, a maternidade, o casamento, a moda feminina, as normalistas, mulheres artistas, o lazer, as prescrições moral, médica, religiosa e civilizatória para adequação e sinalização da participação feminina num universo de papéis naturalizados para elas. Vale ressaltar que os conteúdos da Careta eram pautados em valores e aspectos da camada burguesa da sociedade, portanto, estavam relacionados ao cotidiano das mulheres burguesas, principalmente urbanas. 


\title{
Aspectos teóricos e metodológicos na leitura da Careta
}

A proposta teórico-metodológica desta pesquisa se converge na análise do discurso proposta por Michel Foucault (2010). A educação feminina foi problematizada a partir das relações de poder contidas nos jogos de força, articulados através de saberes para a coerção necessária ao que eventualmente se propunha instituir dentro de regimes de verdade.

\begin{abstract}
As análises de Foucault procuraram, em particular, focalizar as características de nosso próprio regime de verdade. Esse regime possui, com efeito, várias especificidades: a verdade está centrada no discurso científico e nas instituições que o produzem; ela é permanentemente utilizada tanto pela produção econômica quanto pelo poder político; é amplamente difundida, tanto por meio das instancias educativas quanto pela informação; ela é produzida e transmitida sob o controle dominante de alguns grandes aparelhos políticos e econômicos (universidade, mídias, escrita, forças armadas); ela é a forma de "lutas ideológicas" (Revel, 2011, pp. 148149)
\end{abstract}

Eles se dão em uma disposição horizontal, não democrática, expresso em relações nas quais há sobreposição, mas não anulação total de forças; avaliase que há o controle e produção de comportamentos, os quais se propõem homogeneizar, ou a resistência e o questionamento desses regimes de verdade, ao que cabe adequações diante da diversidade das experiências, em um espectro de possibilidades entre o corpo dócil e a resistência.

Dentre os enunciados da revista Careta, muitos circulavam saberes produzidos por instituições como a medicina, a religião, o Estado, que propunham a conformação das mulheres a papéis estabelecidos como lugares de verdade, de credibilidade, regulando as forças do feminino para direcionálas e aumentá-las no propósito das formas de comportamento desejadas. Pela coerção, o regime de verdade se consolida e desdobra porque fundamentado em saberes institucionais (Foucault, 1991).

Assim, papéis ditos femininos são estabelecidos e difundidos, mas conforme se pautam em possíveis sobreposições de força, pode gerar a resistência à ordem posta. Por exemplo, o casamento - a união conjugal nos padrões específicos da sociedade do começo do século XX - como uma prática regulamentada basicamente pela religião e pela medicina não se restringiam ao acato feminino. Por vezes casamentos consentidos ou pela imposição podiam tomar rumos como o adultério. A fuga antes dele também consistia numa alternativa. Tornar-se artista podia ser uma escolha neste sentido, já que para a época implicaria na opção entre marido ou a profissão ${ }^{3}$, para a qual haveria de se levar em conta as consequências do discurso moral sobre a atividade. Mas o que parece prevalecer é a coerção, favorecida pelo 
conjunto de discursos conformadores que direcionava as mulheres para esse destino.

A própria limitação no avanço pelos níveis de escolarização acabava tornando as mulheres mais dependentes dos homens, ou ainda o que Silvia Federici aponta como "infantilização legal das mulheres" na consolidação do Estado de Direito ocidental:

\begin{abstract}
Um dos direitos mais importantes que as mulheres perderam foi o de realizar atividades econômicas por conta própria, como femmes soles. Na França, perderam o direito de fazer contratos ou de representar a si mesmas nos tribunais, tendo sido declaradas legalmente como "imbecis". Na Itália, começaram a aparecer com menos freqüência os tribunais para denunciar abusos perpetrados contra elas. Na Alemanha, quando uma mulher de classe média tornava-se viúva, passou a ser comum a designação de um tutor para administrar seus negócios (...) Em suma, além de uma desvalorização econômica e social, as mulheres experimentaram um processo de infantilização legal (Federici, 2017, pp. 199-200).
\end{abstract}

Com isso, as dificuldades delas de acesso ao espaço público político e educacional as restringia aos cuidados com a casa, os filhos, marido, e na extensão de uma dita "natureza feminina" eram autorizadas à filantropia no caso das burguesas e às mulheres das classes menos favorecidas relegava 0 trabalho doméstico ligados às prendas. Uma das colaborações do discurso religioso para esses limites era o recolhimento feminino como virtude, além do papel de servir ao masculino, conforme será problematizado.

Uma questão relevante neste estudo é que o espaço urbano exigia uma postura das mulheres nas formas de apresentação nesse meio, com recomendações específicas da imprensa, especialmente no recorte de classe. O delineamento do seu comportamento, a moda, os limites para sua entrada na vida social e política provocaram tanto normalizações e conformações na geração de corpos dóceis, quanto novas posturas de embate às instituições produtoras de discursos de verdade.

$\mathrm{Na}$ análise da Careta é possível identificar discursos que representavam o padrão para as relações de gênero, com alguns estereótipos como sobre as sufragistas, representadas com um aspecto masculinizado, as jovens em uma totalidade aspirante ao casamento, com limite de idade e comportamento para tal, e as mulheres burguesas como consumidoras da moda. Com a linguagem humorística e sarcástica da publicação, essas figuras representavam o que se passava na realidade, ainda que de forma distorcida e universalizante. Porém, Implícitas nessas representações estavam divulgadas mulheres reivindicando 0 voto, o casamento como forma de restrição das possibilidades das mulheres aos filhos e marido e suas fragilidades ao expor o cotidiano de descumprimento do propósito monogâmico, bem como a referência ao quadro mundial das 
mulheres que passavam à ocupação de cargos sociais, políticos ou postos de trabalhos ${ }^{4}$.

Para a análise histórica da educação feminina a partir dos discursos veiculados na Careta, é importante uma leitura que leve em conta os jogos de poder e de força, inscritos como enunciados que se materializam como acontecimento naquela realidade passada: "Digamos que a filosofia do acontecimento deveria avançar na direção paradoxal, à primeira vista, de um materialismo do incorporal" (Foucault, 2010, p. 58, grifo meu). Para tanto, uma rede de elementos se destaca, na qual os discursos emergem no acontecimento, que

Não é nem substância, nem acidente, nem qualidade, nem processo; o acontecimento não é da ordem dos corpos. Entretanto ele não é imaterial; é sempre do âmbito da materialidade que ele se efetiva, que é feito; ele possui seu lugar e consiste na relação, coexistência, dispersão, recorte, acumulação, seleção de elementos materiais (Foucault, 2010, p. 57).

O que Foucault propõe em sua filosofia do acontecimento diz respeito à forma de apreensão da realidade histórica de um modo geral. Vem ao encontro dessa questão pensar a materialidade do incorporal fora da esfera metafísicotranscendental. Nessa perspectiva, o incorpóreo está em relação com a materialidade, com o real e não se encontra em planos existenciais diferentes, ele é fruto das relações corpóreas. Pode-se pensar no acontecimento como uma articulação, um movimento da materialidade causado por um conjunto de forças em constante atuação nas relações. Convergência/divergência de forças é o que parece determinar o acontecimento, que não precisa de uma manifestação corporal para se fazer notar, embora aconteça nas relações que se dão pelos corpos.

Do mesmo modo, pode-se pensar a produção de saberes pelas instituições. Tudo se dá no nível das relações, sem assumir necessariamente um contorno externo específico, mas com direção determinada, que se estabelece do ponto da produção de saberes e demonstra uma vontade de verdade, que "é reconduzida, mais profundamente sem dúvida, pelo modo como o saber é aplicado em uma sociedade, como é valorizado, distribuído, repartido e de certo modo atribuído" (Foucault, 2010, p. 17). Nisso o conhecimento é aplicado, valorizado, distribuído, repartido e intenta estabelecer elementos que cumprem dar confiabilidade a enunciados para as regras de funcionamento geral da sociedade.

É importante destacar que Foucault indica que há modos para aplicação de saberes em uma sociedade, o que implica em pensar numa certa organização, com atribuições a um suporte institucional. Assim, "essa vontade de verdade [...] é ao mesmo tempo reforçada e reconduzida por todo um compacto conjunto de práticas" (Foucault, 2010, p. 17). Dessa forma, cumpre

History of Education in Latin America - HistELA, v. 2, e17295, 2019, p. 5 de 15 
pensar em uma rede discursiva como uma malha única, que distribui enunciados de forma dispersa pela sociedade; mesmo que dispersos, os enunciados estão antes em rede, o que implica num conjunto de prescrições que busca coerência do ponto em que estabelece o pertencimento a uma mesma malha. E ainda: é coerência porque pretende a coerção. Pela proposta foucaultiana, torna-se cada vez mais imperativa a percepção das relações existentes entre os enunciados e a produção discursiva na relação com a realidade à qual se aplicam.

\title{
O discurso religioso e sua validação institucional
}

Pensar e elaborar sobre a institucionalização do discurso faz perceber que essa é uma medida para torná-lo coerente, já que parte do contexto de saberes e estabelece o limite do "verdadeiro" e do "falso".

\begin{abstract}
Certamente, se nos situamos no nível de uma proposição, no interior de um discurso, a separação entre o verdadeiro e o falso não é nem arbitrária, nem modificável, nem institucional, nem violenta. Mas se nos situamos em outra escala, se levantamos a questão de saber qual foi, qual é, em sua forma muito geral, o tipo de separação que rege nossa vontade de saber, então é talvez algo como um sistema de exclusão (sistema histórico, institucionalmente constrangedor) que vemos desenhar-se (Foucault, 2010, p. 14).
\end{abstract}

Pelo sistema de exclusão dos discursos-saberes - que, se exclui algum, inclui ou permite a permanência de outro - foram percebidas a apresentação e circulação dos saberes enunciados para a educação feminina na Careta, e nisso o lugar dos saberes religiosos. "Sabe-se bem que não se tem o direito de dizer tudo, que não se pode falar de tudo em qualquer circunstância, que qualquer um, enfim, não pode falar de qualquer coisa" (Foucault, 2010, p. 9).

Interessa pontuar que a imprensa periódica se constitui em uma "sociedade de discurso" que, atualizada à ótica da doutrina circula enunciados amparados pelo crivo das instituições e seus emissores, pois "questiona os enunciados a partir dos sujeitos que falam, na medida em que a doutrina vale sempre como o sinal, a manifestação e o instrumento de uma pertença prévia" (Foucault, 2010, p. 43). O discurso institucionalizado pode ser percebido pelo conjunto de seus enunciados, sendo que o controle não se exerce apenas sobre a forma e seu conteúdo. O pertencimento a uma doutrina põe em jogo tanto o enunciado, a proposição como o sujeito falante, um por meio do outro.

Os discursos da Careta são dispostos em rede de poderes institucionais que se associam às práticas e normas sociais para orientação do comportamento feminino. Por meio da validação dos discursos desde a sua produção, destaca-se para esta parte do estudo a apresentação dos elementos discursivos ligados à religião, em circulação na Careta.

History of Education in Latin America - HistELA, v. 2, e17295, 2019, p. 6 de 15 
Cabe ressaltar que por vezes os indícios são aparentemente sutis, o que se considera do ponto de vista prático, como processos naturalizados para uma sociedade em que predominava a prática cristã católica. Na década de 1910 era recente a proposta de estado laico no Brasil, inaugurado pela Primeira República (1889-1930). Até então, o culto cristão católico era reconhecido como oficial no país, o que lhe assegurava o culto livre, sendo que outros só poderiam ser realizados de forma não pública.

A naturalidade em se considerar os saberes está apresentada a seguir. No diálogo entre um "moço bonito e o filósofo elegante" (Careta, 07 fev. 2014, 1914 , p. 38), o uso de saberes validados histórica e filosoficamente é destacado na relação com o casamento, em que o "moço bonito" pergunta ao outro qual sua opinião sobre ele se casar, ao que the responde o filósofo:

Penso que a natureza tendo que crear um sêr que conviesse ao homem pelas suas proporções físicas ${ }^{5}$, e à creança pelas suas proporções moraes, resolveu o problema fazendo da mulher uma creança grande. É a opinião de Rivarol ${ }^{6}$, que partilho da melhor vontade (Careta, 07 fev. 2014, p. 38).

É importante, inicialmente, destacar o apelo e relação sutil do filósofo em considerar a criação da mulher a partir ou em função do masculino e da maternidade, o que é identificado com o mito da criação descrito no livro cristão católico, o Gênesis. O destaque é para atentar que, até mesmo discursos ditos filosóficos, numa postura pretensamente laica e científica, estavam ainda impregnados das concepções mítico-religiosas, mais precisamente cristãs. A relação entre o trecho da Careta com o mito da criação ${ }^{7}$ se dá pela elaboração de uma origem, em que o saber bíblico propõe que primeiro o homem foi criado pela figura divina, e para lhe servir como companhia é que foi feita a mulher.

A partir disso, a Careta parece então divulgar uma postura de que as relações de gênero estavam postas de forma natural, segundo a opinião daqueles que tiveram seus discursos em circulação naquele momento: o moço bonito como bom pretendente ao casamento, e o filósofo elegante ${ }^{8}$, que pode ser considerado naquela conjuntura como autorizado árbitro da vida social. Ainda interessa ressaltar sobre o modo como está proposta uma dependência da figura feminina em relação à masculina na proposição de que as mulheres foram "criadas" para atender aos homens ou como uma demanda deles.

$\mathrm{Na}$ validação dos saberes relativos às mulheres na Careta, é comum a percepção do agrupamento de valores morais, religiosos e higienistas na composição da regulamentação das práticas como o casamento, a maternidade, a manutenção da família pela submissão feminina, fazendo com que sua aceitação esbarrasse o menos possível na dúvida de sua veracidade e legitimidade, necessário à coerção. Isto Ihe possibilitaria uma circulação livre ou com menos interferência possível das resistências. 
Os discursos adotados a partir de princípios religiosos, ou reforçados por elementos ou indícios da religiosidade, apresentam motivos implícitos para 0 acato a eles. Porque partem dos princípios da fé, estavam estabelecidos como necessários e legítimos já que a autoridade de quem emana essas proposições é divina. Logo inquestionáveis e absolutas.

Dos discursos envolvendo relacionamentos, ou o casamento, percebeuse 0 aspecto de subjugar as forças do feminino à sobreposição masculina, ou 0 propósito de apresentar um papel feminino secundário. A reprodução de afirmações como a máxima "A melhor alegria da mulher, depois de amar, é a de obedecer" (CARETA, 29 set. 1917, p. 19), ou a referência a S. Cypriano, de que "As mulheres são demônios que nos fazem entrar no inferno pela porta do paraizo" (CARETA, 17 ago. 1918, p. 15), apontam para uma conotação religiosa no sentido de um saber mistificado, justificado numa esfera transcendental e de valores morais para a figura feminina nas relações com seus pares.

Ainda neste aspecto mistificado, em texto da seção "Visões da Épocha", assinada por Garcia Margiocco ${ }^{9}$, o autor divaga pelo imaginário popular para falar de sua crença nas bruxas, e termina por afirmar que elas estavam personificadas nas sufragistas. Ao final, a crítica é em relação ao movimento pelos direitos eleitorais femininos.

\begin{abstract}
É de esperar que a maioria das mulheres, elegidas pelos homens ao throno sentimental da graça e da belleza, recusem agora abandonar as ineffaveis harmonias do lar para irem se entregar aos rudes encargos do homem na praça publica. (...) constatei comtudo a existência das bruxas (...) Não duvido que as infelizes bruxas, exoneradas da direção das lendas de feitiçarias, não tivessem entrada no céu e fossem também expulsas do próprio inferno ${ }^{10}$. 0 que afirmo, benzendo-me é verdade, é que ellas estão agora sobre a terra e serão ellas que pela recusa das mulheres novas e bellas, encarregar-se-ão de desempenhar no mundo o duplo papel de homem e mulher... visto não terem sexo... As directoras dessa diabólica legião, representadas por três velhas muito feias ${ }^{11}$, estiveram em tempo no Congresso Federal tratando da sua incorporação ao sexo forte ${ }^{12} \ldots$ chamem-n"as pois de SUFFRAGISTAS ou lobis-homem quem assim o entender. Ellas serão sempre, emquanto houver um moço que renda preitos ao gentil sexo a que ellas pertenceram, as verdadeiras bruxas sobre a terra desligadas do convívio ideal dos salões para a tranqüilidade das mulheres bonitas (Careta, 20 jan. 1917, p. 8, grifo do autor).
\end{abstract}

O destaque ao trecho se dá pelos termos como céu e inferno, diabólica legião e a relação que se faz entre sufragistas e bruxas, levando em conta informações gerais das instituições religiosas que praticaram a Inquisição, executando, entre outros, a caça às bruxas ${ }^{13}$. $\mathrm{O}$ tom didático é bem claro: a adesão feminina ao sufrágio equivalia à sua classificação como bruxa. 
De tal modo algumas concepções se enraízam no discurso de uma época, como a atribuição de direitos políticos somente ao gênero masculino, que $\mathrm{o}$ autor encontrou na Careta a licença para atribuir às mulheres sufragistas o não pertencimento ao próprio gênero feminino, em um não lugar, inclassificáveis, como quando o autor as compara às bruxas, sem entrada no céu e também expulsas do inferno.

Ainda que considerado o tom satírico e humorístico da Careta, o texto revela certa falta de argumentos em seu discurso contrário ao sufrágio feminino. Embora houvessem esforços para elaboração da proibição, como as teses médicas que atribuíam às características biológicas femininas o motivo da negação aos espaços políticos e públicos ${ }^{14}$, não se sustentava pelo pretexto vulgar da beleza feminina; e certamente falar em uma negação da pertença do ato de votar ao sexo feminino revela uma generalização agressiva ao lugar social das mulheres que se sentissem no direito de exercer o sufrágio ${ }^{15}$.

Outro destaque é para a recorrência ao apelo ao feminino nos eventos de caridade apresentado na Careta. O que se percebe nas informações dadas na revista sobre as mulheres na filantropia é que são feitas apresentações diversas, por vezes de forma satírica pelo apelo estético feminino, insinuando a presença delas para atrair empenho e contribuição financeira, às vezes parecendo dar-Ihes parte nas questões sociais e políticas. Invariavelmente, a presença delas na caridade tenta reforçar o papel do cuidado atribuído ao feminino.

Cabe então ressaltar a percepção de um apelo educativo na promoção de eventos de caridade, que ao envolver mulheres, principalmente as adolescentes, se caracterizava como um modo de inculcar nelas o apreço e valorização do cuidado com os outros, principalmente os menos favorecidos.

Para o evento caritativo apresentado a seguir, destaca-se a percepção acerca do processo educativo que ele tende a promover através da experiência proporcionada às mulheres envolvidas. Trata-se da: "Obra de protecção das moças solteiras - festival em benefício dessa Associação". Numa matéria de duas páginas, que conta com muitas fotos (oito no total), é noticiada a realização de "uma significativa homenagem das alunas do curso de inglês às colônias inglesas e americanas domiciliadas no Rio de Janeiro". O evento teve fim filantrópico já dito no seu título. Sobre a "Sociedade de Proteção às Moças Solteiras" é feita breve consideração a respeito, que tendo sido criada há pouco já contava com a ajuda de numerosas famílias da elite social. A sua "utilidade está fora de qualquer dúvida, sobretudo nas grandes cidades em que a honestidade das moças pobres está exposta além das tentações vulgares, às contingências da miséria" (CARETA, 13 nov. 1915, p. 17).

A notícia se apresenta num tom de destaque à benfeitoria da elite social. Pode-se ressaltar a relação que se fazia entre moças pobres solteiras e a necessidade de proteção, já que não contavam com a figura masculina ao seu lado e poderiam vir de modelos familiares chefiados por mulheres. Institui-se 0 History of Education in Latin America - HistELA, v. 2, e17295, 2019, p. 9 de 15 
casamento como necessidade delas, e conforme já mencionado como inferiores nas relações de gênero e, por isso, dependentes da figura masculina ao seu lado.

Em uma perspectiva educacional para análise dessa notícia pode ser destacado o potencial educativo da ação, em que os enunciados que o evento conteve são de uma esfera relativa à sexualidade das alunas por abordar aspectos relativos à necessidade da união conjugal, à qual elas eram via de regras direcionadas.

A relação dos discursos, apresentados em rede para melhor efeito, pode ser percebido nesse exemplo. A relação com a questão religiosa, apesar de não estar mencionada explicitamente, pode ser percebida por meio da instituição do casamento como melhor destino para as mulheres. Não é preciso mencionar o aspecto da demanda religiosa para que ela esteja presente no imperativo moral.

E ainda no apelo ao menos favorecido, a ligação entre caridade e religião é apresentada em outra situação. Por meio de uma foto em uma escadaria, retratando "cem pobres beneficiados", estão à frente crianças descalças, e se nota a presença de muitos negros. A ação caritativa, por direção da Sra. Regina San-Juan, teve vínculo com a Igreja Católica, o que é afirmado na matéria. $O$ ato é ressaltado como uma "dádiva", com ação após a missa na Igreja São João Batista, na mesma ocasião da comemoração do descobrimento do Brasil. Na descrição do acontecimento, percebe-se uma ênfase à "generosidade das ilustres senhoras", também chamadas "nobres damas" (Careta, 13 nov. 1915, p. 17).

A partir do que se poderia alcançar títulos de nobres damas, realçando o comportamento adequado a se produzir, é interessante contrastar com a informação anterior em que buscou-se repreender a atitude das sufragistas na negação e punição àquelas que ousasse fazê-lo. Aqui a produção de comportamento é assertiva e se dá no elogio e afirmação da ação caritativa, projetada a partir da prática religiosa.

Explorando um pouco mais os enunciados da revista, é importante situar a fotografia, que se considera não tratar-se "de algo inscrito na natureza, mas de artefatos da cultura produzidos pelos homens e perpassados de visões de mundo que não são neutras, mas carregados de subjetividade $e$ condicionamentos ligados ao lugar de produção" (André, 2009, p. 155). Assim, justifica-se a leitura das fotografias, analisadas na Careta, como enunciados, assim como textos e charges, que a partir de sua produção são colocados em circulação na revista.

Neste aspecto, a seção sempre em destaque nas edições da Careta, "Os instantâneos", retratavam momentos comuns ao cotidiano de algumas mulheres, principalmente no cenário carioca, em passeios pelas praças, avenidas, Jokey Club ou praia. Entre esses registros estão aqueles feitos de 
mulheres à saída da missa. Nesta menção específica ao instantâneo, o que dá uma conotação de capilaridade do poder e seu trânsito nas práticas naturalizadas como próprias para uma boa conduta está na informação de que, se a revista fazia circular esse tipo de informação - mulheres à saída da missa - é porque alguma relevância ela apresentava. Pode-se pensar nisso como meio de promover a religiosidade das mulheres leitoras da Careta no período de sua circulação, e para a pesquisa histórica essa informação ajuda a corroborar que a prática religiosa era algo valorizado para aquela sociedade, no âmbito burguês pelo qual circulava. O discurso religioso estava em pauta na Careta e em vigor no período.

O que "a saída do templo" - legenda comum para os instantâneos acarreta não é simplesmente o ritual cristão católico, mas toda uma rede de enunciados ligada à moral cristã, que designava para as mulheres papéis específicos tanto dentro da família, como na vida social, em sua maioria de cunho resignatário.

Ainda relevante para a proposta, destaca-se algumas situações relacionadas às danças. Uma delas foi feita em uma conferência realizada por um sacerdote e noticiada na Careta: "A dança de qualquer espécie que seja, é uma instituição immoral e perniciosa" (Careta, 27 jul. 1918, p. 24). Em uma situação anterior, uma charge de J. Carlos ironizava a opinião da igreja: "Pequena alteração; -Não, minha senhora. A lgreja não condena o tango. Admite-o, mas com música de Beethoven e passos de minuetto" (Careta, 07 mar. 1914, capa).

Delinea-se nesses enunciados a preocupação da esfera religiosa no cuidado com os corpos, por meio da orientação sobre a dança. Pode-se pensar no cuidado com a sexualidade que essa interdição propõe, e o discurso apresentado pela religião sugere uma autoridade na elaboração e pronunciamento dos seus discursos: de inspiração divina revelada por seus representantes na hierarquia clerical. Sobre essa relação entre a dança como acontecimento ou prática social e a sexualidade, pode-se pensar no caráter restritivo que se impõe à segunda automaticamente ao que se propõe à primeira.

\footnotetext{
O que não é regulado para a geração ou por ela transfigurado não possui eira, nem beira, nem lei. Nem verbo também. É ao mesmo tempo expulso, negado e reduzido ao silêncio. Não somente não existe, como não deve existir e à menor manifestação fá-lo-ão desaparecer - sejam atos ou palavras.(...) Isso seria próprio da repressão e é o que a distingue das interdições mantidas pela simples lei penal: a repressão funciona, decerto, como condenação ao desaparecimento, mas também como injunção ao silêncio, afirmação de inexistência e, consequentemente constatação de que, em tudo isso, não há nada para dizer nem para ver, nem para saber (Foucault, 1988, p. 10).
} 
Vale ressaltar que não se afirma que o costume das danças cessou, mas sim sobre o caráter discursivo religioso de restrição e interdição aos corpos e sexualidade. Também a relevância na circulação dessas informações, a autorização desses discursos, ainda que de forma sarcástica, em outra em tom de disseminação da fala. O que interessa é ressaltar que os discursos religiosos estavam aliados a práticas sociais e as considerações eram pontuais, fazendo-se de forma explicita ou implícita, mas aqui apresentados como parte constituinte das autorizações e restrições para o feminino, como parte de discursos para a orientação dos comportamentos.

\section{Considerações}

Como visto para este trabalho, acerca da formulação de discursos para a educação feminina - neste caso pela imprensa, - há que se ter autorização tanto na sua produção quanto para colocá-los em circulação: "Ninguém entrará na ordem do discurso se não satisfizer a certas exigências ou se não for, de início, qualificado para fazê-lo" (Foucault, 2010, p. 37). De um modo geral, considera-se o discurso para a educação das mulheres na Careta de formulação patriarcal, ou de um consenso institucional em que predominavam os discursos de ordem patriarcal. Sobre esse critério, é bem evidente a participação da Igreja Católica, composta em sua organização basicamente por homens.

Isto pode ser afirmado devido à estrutura geral das instituições, de predominância masculina, que se ocupavam dos enunciados para a educação das mulheres no período. Na medicina, as mulheres tinham uma entrada mínima; no governo político, elas nem mesmo participavam do processo eleitoral no período; na guerra, considerada também assunto político, elas participavam como suporte para as necessidades ocasionadas pelo conflito; na filantropia, de um modo geral, as mulheres pareciam ter uma participação mais de adequação a bons costumes e práticas sociais solidárias; o discurso religioso que, ainda que as chamasse à participação, era para moralizá-las, para normalizar o gênero feminino e reproduzir os saberes da instituição.

$\mathrm{Na}$ convergência de propósitos, o discurso religioso aparece fundamentado em seus saberes elaborados ao longo de quase dois milênios de existência enquanto instituição. Sustentado no argumento da inspiração divina naquilo que determina em seus enunciados, estes tornavam-se orientações para a vida prática em seus pontos mais capilares e extensivos às práticas cotidianas. Com isso pautavam comportamentos e até mesmo os sentimentos que os motivavam, como a compaixão na sensibilização e responsabilização pelo outro, a valorização da integralidade no que diz respeito aos padrões de moralidade ou a até mesmo no sentimento que mobiliza $o$ 
pertencimento ao todo na condição de uma participação secundária à figura masculina.

\section{Referências}

Almeida, M. M. (1994). Na trilha de um andarengo: Alcides Maya (1877-1944). Porto Alegre: EDIPUCRS.

Anais da Câmara dos Deputados. (1916). Pronunciamento do Deputado Mauricio de Lacerda. Rio de Janeiro.

ANDRÉ, R. G. (2009). Entre o contexto e a linguagem: O discurso fotográfico e a pesquisa histórica. Domínios da imagem, 3(5), 153-162.

Careta. (1914). Rio de Janeiro: Editora Kosmos.

Careta. (1915). Rio de Janeiro: Editora Kosmos.

Careta. (1916). Rio de Janeiro: Editora Kosmos.

Careta. (1917). Rio de Janeiro: Editora Kosmos.

Careta. (1918). Rio de Janeiro: Editora Kosmos.

D’Incao, M. Â. (1997). Mulher e família burguesa. In L. D Priori (Org.), História das mulheres no Brasil. São Paulo: Contexto.

Federici, S. (2017). Calibã e a bruxa: Mulheres, corpo e acumulação primitiva (Coletivo Sycorax, Trad.). São Paulo: Elefante.

Foucault, M. (1988). História da sexualidade. In M. Foucault. A vontade de saber (M. T. Albuquerque \& J. A. G. Albuquerque, Trad.). Rio de Janeiro: Edições Graal.

Vozes.

. (1991). Vigiar e punir: Nascimento da prisão (38 ${ }^{\underline{a}}$ ed.). Petrópolis:

. (2005). Em defesa da sociedade: Curso no Collège de France (19751976) (M. E. Galvão, Trad.). São Paulo: Martins Fontes.

. (2010). A ordem do discurso (20a ed., L. A. Sampaio, Trad.). São

Paulo: Edições Loyola.

Maluf, M. \& Mott, M. L. (2006). Recônditos do mundo feminino. In N. Sevcenko (Org.), História da vida privada no Brasil 3: República: Da Belle Époque à era do rádio. São Paulo: Companhia das Letras.

Rago, M. (2014). Amores ilícitos na Paris de Émile Zola. Revista História e Perspectivas, (50), 45-88.

Revel, J. (2011). Dicionário Foucault (A. A. Silva, Trad.). Rio de Janeiro: Forense Universitária.

Varikas, E. (2009). Universalismo e particularismo. In H. Hidrata, F. Laborie, H. Le Doaré \& D. Senotier (Orgs.), Dicionário Crítico do Feminismo (pp. 266-270). São Paulo: Editora UNESP (FEU).

Volusia, E. (1983). Eu e a dança. Rio de Janeiro: Revista Continente Editorial. 


\section{Notas}

' Este estudo é parte da dissertação de mestrado "A revista Careta e a educação das mulheres: uma dispersão discursiva para a normalização feminina no contexto urbano (1914-1918)", defendida em 2012 no Programa de Pós-Graduação em Educação da Universidade Federal de São João del-Rei. Esta é uma versão revisada do trabalho "A revista Careta e a circulação de saberes religiosos na validação dos discursos para a educação feminina", apresentado no IX Congresso Brasileiro de História da Educação (2017, João Pessoa: Paraíba).

${ }^{2} \mathrm{Na}$ hierarquia da Igreja Católica, ou o clero, todos os cargos disponíveis são para o sexo masculino e atualmente dispostos da seguinte maneira: o Papa, comanda a Igreja universalmente; Cardeais, escolhidos pelo Papa e estão no topo da hierarquia ; Bispos e Arcebispos que se organizam juridicamente por regiões, as chamadas dioceses, que são unidades geográficas, abrangendo cidades e unidades menores; Padres que são sacerdotes e cuidam de atividades cotidianas da prática católica (fonte: www.ebc.com.br, visitado em 25 mar. 2019).

${ }^{3}$ Eros Volusia (1914-2004), bailarina de carreira profissional na primeira metade do século XX relata em suas memórias porque não se casou, em referência a pergunta que segundo ela era recorrente: "Tive vários pretendentes à minha mão, mas todos exigiam que eu me divorciasse da dança e como isso seria o mesmo que cortar-me as asas eu jamais concordei com essa separação" (Volusia, 1983, p. 124).

${ }^{4} \mathrm{Na}$ edição de 20 de março de 1915 (p. 34), a Careta publicou fotografia da "Scena da vida atual de Paris" em uma referência à situação provocada pela guerra, em que "Mulheres substituem as funções de cobradores e condutores dos bonds".

${ }^{5}$ Sobre a atribuição da proporção física das mulheres para atender aos homens, encontra-se citado no texto de Maluf e Mott (2006, p. 399) um trecho de Ercilia Nogueira Cobra, que na década de 1920 questionou o lugar da submissão sexual feminina na escrita de dois livros, Virgindade anti-higienica e Virgindade inútil. Com isso percebe-se a resistência aos discursos morais e reguladores sobre a sexualidade feminina por mulheres do início do século XX. O tom de resistência de Ercília é bem objetivo: "Os homens no afã de conseguirem um meio prático de dominar as mulheres, colocaram-lhe a honra entre as pernas, perto do ânus, num lugar que, bem lavado, não digo que seja limpo e até delicioso para certos misteres, mas que nunca jamais poderá ser sede de uma consciência. Nunca!! Seria absurdo! Seria ridículo, se não fosse perverso. A mulher não pensa com a vagina nem com o útero".

${ }^{6}$ Antoine de Rivarol (1753-1801), foi um escritor francês.

7 O mito da criação do mundo encontra-se no Gênesis, o primeiro do conjunto de livros da Bíblia, concebida pela cultura cristã como escritos inspirados divinamente, portanto dotada de credibilidade para a orientação de seu público seguidor.

${ }^{8}$ A caracterização do filósofo da história como elegante pode conferir ao seu discurso ainda mais credibilidade, na medida em que a Careta propunha para seus leitores que a elegância era sinal de bons hábitos, boa educação e conduta.

${ }^{9} \mathrm{O}$ autor é mencionado num livro sobre literatura brasileira como crítico literário e escritor de Ruínas Vivas (1911): "(...) José Garcia Margiocco - que então [1911] escrevia n"Reforma de Porto Alegre, mas posteriormente atuaria na imprensa do centro do país, em particular na revista Careta (...)" (Almeida, 1994).

${ }^{10}$ Segundo a tradição católica, esse não lugar, nem inferno nem o céu, é chamado limbo.

${ }^{11}$ A respeito das sufragistas em questão, não há nomes nem informações sobre a situação mencionada, da visita de sufragistas ao Congresso. Porém, a revista menciona constantemente Bertha Lutz e Deolinda Daltro como figuras do sufrágio. Barbara Salesia poderia ser um terceiro nome, já que aparece numa das pequenas narrativas da Careta, em que ela é descrita como quem andava pregando os direitos da mulher (CARETA, 07 abr. 1917, p. 10).

${ }_{12}$ Tramitou na Camara dos Deputados, ao final do ano de 1916, uma petição sobre o voto da mulher, remetida à Comissão de Constituição de Justiça pelo então Deputado Mauricio de Lacerda, do qual está registrado o pronunciamento nos Anais da Camara dos Deputados (RJ), de 22 de dezembro de 1916 (p. 205-206), que assim o inicia: "Recebi do Partido Republicano Feminino uma representação contra o facto de, na reforma eleitoral, não ter sido incluída qualquer disposição expressa a respeito do voto da mulher; e estando essa reclamação fundamentada em um precedente verificado no Brasil - do exercício desse direito pela mulher achei interessante a questão e tomei entre as mãos a representação que encaminho, por intermédio da Mesa, à Comissão respectiva". O partido mencionado foi fundado no Rio de Janeiro em 1910 por Leolinda Daltro, uma das possíveis sufragistas em questão no texto da Careta, possivelmente acompanhada por Bertha Lutz, recorrente nas manifestações sufragistas. Barbara Salesia poderia ser um terceiro nome, já que aparece numa das pequenas

History of Education in Latin America - HistELA, v. 2, e17295, 2019, p. 14 de 15 
narrativas da Careta, em que ela é descrita como quem andava pregando os direitos da mulher (CARETA, 07 abr. 1917, p. 10).

13 "Foi a Constitutio Criminalis Carolina - o Código Legal Imperial promulgado pelo rei católico Carlos V em 1532 - que estabeleceu que a bruxaria seria penalizada com a morte. $\mathrm{Na}$ Inglaterra protestante, a perseguição foi legalizada por meio de três Atos do Parlamento, aprovados, respectivamente, em 1542, em 1563 e em 1604, sendo que o último introduziu a pena de morte inclusive na ausência de danos a pessoas ou a coisas. Depois de 1550, na Escócia, na Suíça, na França e nos Países Baixos Espanhóis, também foram aprovadas leis e ordenanças que fizeram da bruxaria um crime capital e incitaram a população a denunciar as suspeitas de bruxaria. Estas foram republicadas, nos anos seguintes, para aumentar a quantidade de pessoas que podiam ser executadas e, novamente, para fazer da bruxaria por si só, e não dos danos que supostamente provocava, um crime grave" (Federici, 2017, pp. 297298)

${ }_{14}$ "Em La donna delinquente e la prostituta, de 1896, Cesare Lombroso [médico e criminologista do final do século XIX) realiza um minucioso estudo das diferentes espécies de insetos, animais e humanos, partindo dos povos mais primitivos aos mais civilizados, para mostrar como o sentido do progresso se caracteriza universalmente pela predominância do macho e do patriarcado. Segundo ele, em todas as formas de vida animal, das mais primitivas e já extintas às atuais, a evolução das espécies se orientou no sentido inverso da predominância das fêmeas sobre os machos. Assim, a sociedade mais evoluída, isto é, aquela em que ele vive, se caracteriza pela absoluta dominação masculina, já que sempre foram os homens que prevaleceram não apenas por uma constituição física mais fortalecida e melhor acabada, como por terem contribuído decisivamente para o desenvolvimento das ciências e das artes. O progresso, portanto, é para ele um fenômeno exclusivamente masculino" (Rago, 2014, p. 57).

${ }^{15}$ Acerca do universalismo, em seus aspectos conceitual e histórico, é de que "ele suspeita não só do particularismo dos interesses privados, mas também da singularidade irredutível do ser humano, de sua capacidade de expressar, em termos generalizáveis, seus desejos e necessidades" (Varikas, 2009, p. 268). Isso, em relação às mulheres, sobre suas demandas e reivindicações, dentre elas as educacionais, de ocupação de espaços na esfera pública/política, para elaboração de discursos, torna-se ofensivo ao universalismo. Se o conceito, naturalizadamente, supõe a inclusão de todos os indivíduos, não haveria justificativa para o tratamento particular da condição feminina: essa é a premissa. 